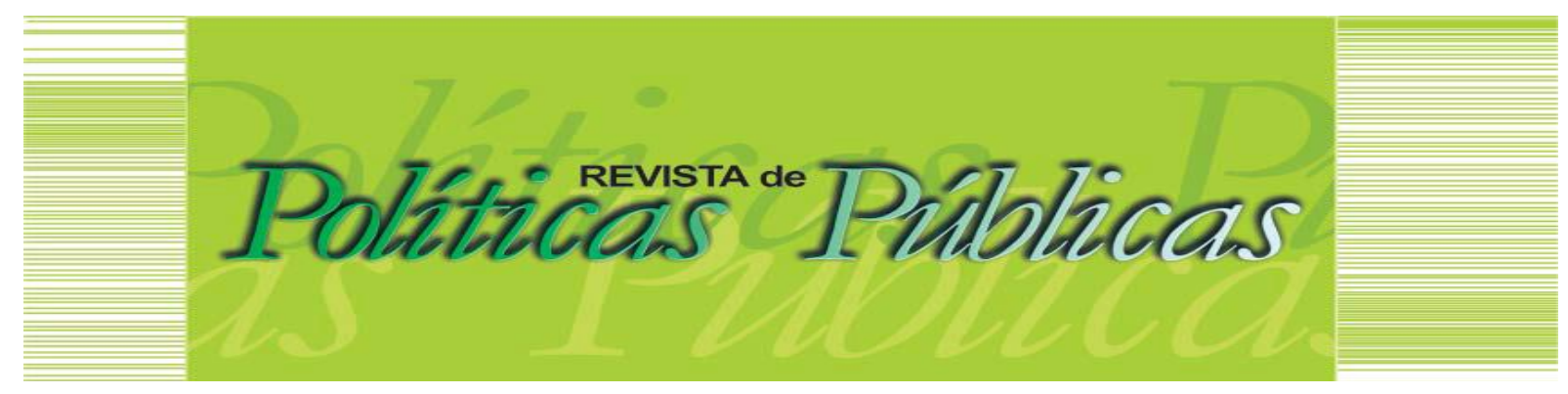

\title{
POLÍTICAS DE DERECHOS HUMANOS EN ARGENTINA (2003-2015): interpretaciones y controversias en el Movimiento de DDHH
}

Enrique Salvador Andriotti Romanin ${ }^{1}$ Carolina Sofía Tavano ${ }^{2}$

\begin{abstract}
Resumen:
El artículo propone analizar el vínculo entre algunas organizaciones de derechos humanos de la Argentina con los gobiernos kirchneristas, observando, por un lado, las políticas públicas reparatorias más destacadas vinculadas al tratamiento del pasado dictatorial (1976-1983), impulsadas desde diferentes agencias estatales en el período 2003-2015; y, por otro lado, la repercusión (o no) que tuvieron esas políticas en las representaciones sobre el gobierno y el Estado construidas al interior de las organizaciones que cooperaron y confrontaron con los gobiernos kirchneristas. El abordaje metodológico es cualitativo, permitiendo el tratamiento de diferentes fuentes: entrevistas, documentos de las organizaciones y manifestaciones en la prensa escrita, consultándose, también, documentos oficiales, leyes y decretos, y manifestaciones de funcionarios para indagar las políticas públicas desplegadas en ese período.
\end{abstract}

Palabras clave: Derechos Humanos. Políticas Públicas. Estado. Movimiento de Derechos Humanos. Kirchnerismo

HUMAN RIGHTS POLICIES IN ARGENTINA (2003-2015): interpretations and controversies in the Human Rights Movement

\section{Abstract:}

This article proposes to analyze the link between some Human Rights organizations from Argentina and the kirchner governments, observing, on the one hand, the public policies that stood out most, linked to the treatment of the dictatorial past (1976-1983), promoted by different state agencies between 2003-2015, and on the other hand, the repercussions (or not) that those public policies had in the government and State representations built within the organizations, which cooperated and confronted the kirchner governments. The methodological approach is qualitative, allowing the treatment of different sources: interviews, documents from the organizations and their testimonies in the written press, also consulting official documents, laws and decrees, and testimonies of public officials, to study the public policies developed in those years.

Keywords: Human Rights. Public Policies. State. Human Rights Movement. Kirchnerism

Recebido em: 16/08/2018 Aprovado em: 28/03/2019 DOI: http://dx.doi.org/10.18764/2178-2865.v23n1p421-440

\footnotetext{
1 Lincenciado en Sociologia. Doutor en Ciencias Sociales pelo Consejo Nacional de Investigaciones Científicas y Técnicas (CONICET) de lo Centro de Estudios Sociales y Políticos (CESP) de Universidad Nacional de Mar del Prata (UNMDP). Endereço: Funes 3350, Departamento de Sociologia, Facultad de Humanidades, Universidad Nacional de Mar Del Plata. Cp 7600, Mar Del Palta, Buenos Aires, Argentina. E-mail: romanin@mdp.edu.ar

2 Licenciado en Sociologia CONICET/CESP-UNMDP. Funes 3350, Departamento de Sociologia, Facultad de Humanidades, Universidad Nacional de Mar Del Plata. Cp 7600, Mar Del Palta, Buenos Aires, Argentina. E-mail: carotavano@gmail.com
} 


\section{INTRODUCCIÓN}

En los últimos años se han producido en Argentina distintos debates acerca de la relación entre algunas de las organizaciones emblemáticas del Movimiento de derechos humanos (en adelante MDH) del país y los diferentes gobiernos Kirchneristas'. Este debate que involucra académicos, periodistas y políticos tiene como epicentro un dato insoslayable: la existencia de un grupo de organizaciones de derechos humanos (DDHH) que manifestaron su apoyo a las políticas reparatorias ${ }^{2}$ impulsadas por esos gobiernos y que, en su postura más radical, manifestaron su incorporación al proyecto político kirchnerista ${ }^{3}$.

Algunos trabajos han intentado avanzar en la explicación de las continuidades y transformaciones en las modalidades de vinculación entre organizaciones de DDHH y el gobierno nacional durante el período 2003 - 2015, destacando distintos aspectos del asunto: por un lado, han planteado que dicha vinculación es un efecto de la cooptación económica y financiera por parte de los gobiernos kirchneristas (GASULLA, 2012) o que es el resultado de un mecanismo prebendario basado en subsidios, retornos y apoyo político que permitió al gobierno apropiarse de la bandera de los DDHH, con el objetivo de lograr una mayor legitimación de sus políticas. (ROMERO, 2011). Por otro lado, y en gran medida discutiendo las explicaciones economicistas, otros autores han señalado la importancia de comprender las transformaciones en las modalidades de vinculación a partir del discurso de los gobiernos kirchneristas y la adhesión política/ideológica y afectiva que suscitó entre los integrantes de algunas organizaciones de DDHH. (ANDRIOTTI ROMANIN, 2015; MONTERO, 2013; MORALES, 2012; RETAMOZO, 2011).

Una mirada rápida a las posturas adoptadas por las organizaciones de DDHH muestra la importancia de avanzar en las investigaciones acerca de su vínculo con los gobiernos kirchneristas durante el periodo 2003-2015, pues este plantea numerosos interrogantes: ¿Cómo interpretaron estas organizaciones las políticas en relación al pasado dictatorial desplegadas por estos gobiernos? ¿Qué controversias generaron estas políticas entre las organizaciones de DDHH y por qué una parte no modificó su postura de confrontación con el gobierno? ¿Qué transformaciones en el marco interpretativo de las organizaciones se produjo a partir de su vinculación con el gobierno? ¿Cómo se explica la integración de algunas de aquellas en un proyecto político identificado con el gobierno kirchnerista?

Para acercarnos a responder estos interrogantes, analizaremos las políticas más destacadas en materia de reparación impulsadas desde diferentes agencias estatales durante el período 2003-2015, puntualmente aquellas orientadas al tratamiento del pasado referido a la última dictadura militar que tuvo lugar en Argentina entre 1976 y 1983. Por último, intentaremos dar cuenta 
acerca de la repercusión, o no, que tuvieron estas políticas en las representaciones sobre el gobierno y el Estado construidas al interior de las organizaciones del MDH que cooperaron y confrontaron con los gobiernos kirchneristas.

Para la realización de este trabajo utilizamos un abordaje metodológico cualitativo, que nos permitió el tratamiento de diferentes fuentes de información, tales como entrevistas en profundidad, documentos de las organizaciones de DDHH y manifestaciones en la prensa escrita, especialmente en medios gráficos de alcance nacional. Asimismo, a fin de indagar en las políticas públicas del período, consultamos documentos oficiales, leyes y decretos, como también manifestaciones de funcionarios acerca de las decisiones tomadas por los distintos niveles del Estado.

\section{ACLARACIONES METODOLÓGICAS}

Al pensar cómo abordar la relación entre el gobierno y el MDH surgieron varios problemas metodológicos. El primero consistió en desnaturalizar la idea de Estado y su accionar como ejecutor de políticas públicas orientadas al tratamiento del pasado reciente, en particular de los crímenes cometidos durante la dictadura militar. En relación a las políticas reparatorias vinculadas a aquel pasado dictatorial, por un lado, prestamos atención a las medidas que cobraron mayor visibilidad, impulsadas desde el Poder Ejecutivo, Legislativo (conducente a la sanción de leyes específicas) o el Poder Judicial (fundamentalmente en lo que respecta a los procesos judiciales por causas de lesa humanidad) durante el periodo 2003 - 2015. Con este recorte no pretendemos ignorar la existencia de medidas y políticas públicas impulsadas por otros gobiernos ${ }^{4}$, sino detenernos en un período en el cual se produjeron transformaciones significativas al interior del MDH. Asimismo, buscamos aproximarnos a comprender si existió una política de DDHH y cómo se gestó, o, por el contrario, si en lugar de una política encontramos una constelación de medidas guiadas por lógicas diferentes.

Para poder realizar un análisis más detallado de las variaciones que se pudieron haber dado en cuanto a la inversión específica en el área, observamos los Proyectos de Presupuesto Nacional desde el año 2002 al 2017 correspondientes al Ministerio de Justicia y Derechos Humanos ${ }^{5}$. Específicamente, tomamos el presupuesto del programa más significativo relacionado al terrorismo de Estado durante la última dictadura: el Programa 26 Promoción y defensa de los Derechos Humanos (cuyos objetivos también han variado a través de los diferentes gobiernos, pero será objeto de análisis más adelante). Y a partir del año 2009, sumamos al estudio otro programa específico que ingresó en ese entonces en la órbita del Ministerio: el Programa 36 Fortalecimiento de Procesos Judiciales contra Delitos de Lesa Humanidad. Aunque el foco del trabajo está puesto en analizar el período kirchnerista (2003-2015), en los análisis presupuestarios se incorporaron también datos de los años 2001-2002, para dar cuenta de algunos acontecimientos significativos en materia de DDHH durante este breve 
período de transición; y también los años 2016-2017, para observar al menos de forma preliminar los cambios de tendencia en las políticas de DDHH que conllevó la llegada de la Alianza Cambiemos ${ }^{6}$ al gobierno nacional en diciembre de 2015.

Para aproximarnos a las representaciones sobre el gobierno, el Estado y la política construidas al interior del MDH, analizaremos los discursos públicos con motivo de los actos del 24 de marzo $^{7}$ del Encuentro Memoria, Verdad y Justicia ${ }^{8}$ (EMVyJ) y a partir del 2007, los documentos presentados en conjunto por algunas organizaciones de $\mathrm{DDHH}$ que se desprendieron de aquel grupo original: Abuelas de Plaza de Mayo (APdM), Madres de Plaza de Mayo línea fundadora (MPdM), Familiares de Desaparecidos y Detenidos por Razones Políticas (FDDRP), una parte de H.I.J.O.S. y ocasionalmente, Hermanos de desaparecidos por la Verdad y la Justicia (HDVJ). Consideramos que esa primera asociación y su posterior ruptura nos permiten aproximarnos a las tensiones que caracterizan al MDH y aprehender al mismo tiempo sus diferentes marcos interpretativos acerca del Estado.

Seleccionamos estos documentos por varios motivos: fueron leídos en contextos de actos masivos, con gran difusión, por ende intentan sintetizar la postura pública de las organizaciones; los documentos se elaboran de manera continuada desde el año 1996, lo que permite hacer un seguimiento y lectura comparada; y además, la elaboración de cada documento es producto de un largo trabajo por parte de las organizaciones previo al acto, conducente a alcanzar una posición consensuada, plasmando por consiguiente el núcleo duro de demandas y posicionamientos que son compartidos por los heterogéneos actores que conforman los dos colectivos de organizaciones.

\section{POLÍTICAS REPARATORIAS SOBRE EL PASADO DICTATORIAL}

Desde el año 2003, las políticas reparatorias vinculadas a los crímenes cometidos durante la última dictadura militar en Argentina comenzaron a convertirse en un tema de creciente centralidad en la agenda del gobierno de Néstor Kirchner. Esto se tradujo en un conjunto de medidas promovidas en muchos casos desde el Poder Ejecutivo, las cuales también fueron acompañadas por el Poder Legislativo o confluyeron con proyectos impulsados independientemente desde este espacio. Entre las políticas más destacadas, se pueden mencionar:

- La derogación de las Leyes de Obediencia Debida y Punto Final (Ley Nacional $n^{0} 25.779$ del 21 de agosto de 2003); y la declaración de nulidad e inconstitucionalidad de Indultos.

- La extensión de las políticas reparatorias para las personas que sufrieron de manera directa violaciones a los Derechos Humanos (Ley Nacional $n^{0} 25.914$ del 04 de agosto de 2004 y $n^{0}$ 26.564 del 25 de noviembre de 2009). 
- La creación del Programa Plan Nacional de Derechos Humanos (Decreto Nacional N 696,14 de mayo de 2010).

- La creación del Archivo Nacional de la Memoria (2003), del Espacio para la Memoria y para la promoción y defensa de los Derechos Humanos, en el predio de la ex $\operatorname{ESMA}^{9}$ (2007), el Centro cultural Haroldo Conti (2008) y el Centro de Asistencia Integral a las víctimas del Terrorismo de Estado, Dr. Fernando Ulloa (2009), entre otros espacios ${ }^{10}$.

- La jerarquización de CONADI (Decreto Nacional n 715, 09 de junio de 2004) y el Banco de Datos Genéticos (Ley Nacional n 26.548 del 18 de noviembre de 2009) entre otras ${ }^{11}$.

- Sanción de la Ley Nacional de Sitios de Memoria, n² 26.691, 29 de junio de 2011.

- La señalización de alrededor de 200 lugares que funcionaron como centros clandestinos de detención durante la última dictadura (desde el año 2005 al 2015)12.

A su vez, desde el Poder Judicial se revitalizaron los procesos vinculados a crímenes de lesa humanidad, en especial a partir de la declaración de inconstitucionalidad y nulidad de las Leyes de Obediencia Debida y de Punto Final13, como también de los decretos de indultos otorgados durante el gobierno de Carlos Menem ${ }^{14}$. La reapertura de procesos judiciales se inició en el año 2005 y condujo a una primera sentencia sobre esos crímenes en 2006, inaugurando un nuevo ciclo en lo que refiere a la búsqueda de justicia. Desde aquel año, se incrementaron de manera progresiva la cantidad de juicios por lesa humanidad finalizados (alcanzando su pico máximo en los años 2012-13 - Cuadro 1) y llegando al número de casi 3000 acusados por estos crímenes al año 2016 (Cuadro 2). Este último movimiento judicial podría interpretarse como el conjunto de acciones que más repercusión tuvo en el espacio público en materia de DDHH, reconocido como un gran avance del Estado sobre la impunidad de aquellos crímenes cometidos. (ANDRIOTTI ROMANIN, 2015).

\section{Cuadro 1 - Juicios por delitos de lesa humanidad finalizados}

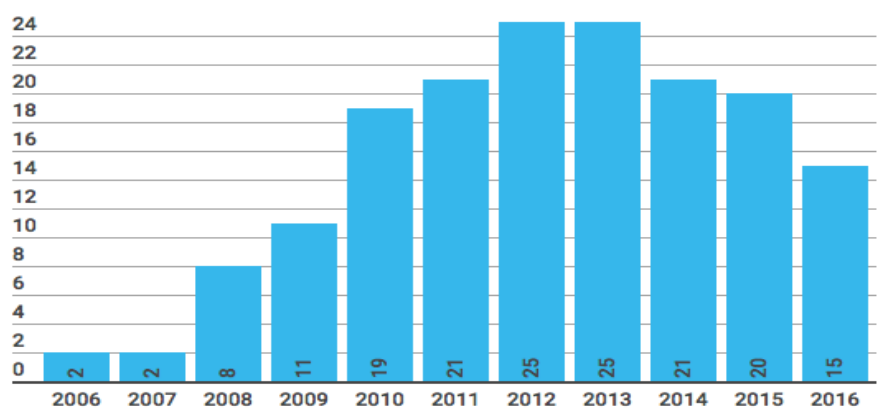

Argentina. Datos actualizados el 30/09/2016.

Fuente: CENTRO DE ESTUDIOS LEGALES Y SOCIALES. Estadísticas / proceso de Justicia delitos de lesa humanidad. Ciudad de Buenos Aires, 2016. Disponible en: https://www.cels.org.ar/web/estadisticas-delitos-delesa-humanidad/. Acceso el: 30 sept. 2016. 


\section{Cuadro 2 - Personas acusadas por delitos de lesa humanidad}

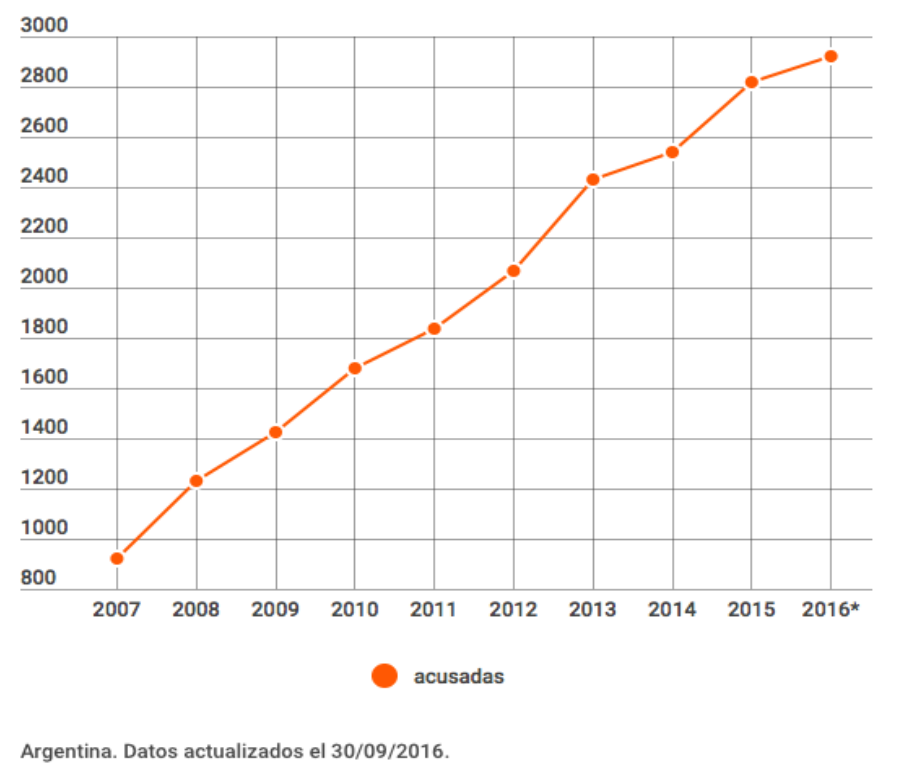

Fuente: (CENTRO DE ESTUDIOS LEGALES Y SOCIALES, 2016).

Otro rasgo que da cuenta de las características que tuvo la política de DDHH durante los gobiernos kirchneristas tiene que ver con el perfil del personal político incorporado a la gestión: a partir del año 2003, ocuparon cargos jerárquicos (y también de otros niveles) en diversas áreas estatales personas vinculadas a la defensa de los $\mathrm{DDHH}$, ya sea por su trayectoria profesional, como también militantes asociados a la lucha contra la impunidad de los crímenes cometidos durante la última dictadura. En este sentido, el perfil de los funcionarios ${ }^{15}$ que estuvieron al frente de la Secretaria de Derechos Humanos de Nación durante el período analizado, permiten identificar este elemento compartido: una fuerte identificación con el MDH a partir de su carácter de victimas y su militancia política en la lucha contra la impunidad de los crímenes cometidos durante el terrorismo de Estado. De manera hipotética, planteamos que esta decisión buscó marcar la intención de profundizar y ampliar las políticas vinculadas a la violación de $\mathrm{DDHH}$ durante el terrorismo de Estado, pero también constituyeron un modo de reivindicar como propia la lucha por los DDHH por parte del gobierno, mediante la apropiación del capital simbólico de aquella causa impulsada fundamentalmente por el $\mathrm{MDH}$, la cual gozaba por aquel entonces de un amplio reconocimiento y legitimidad por una parte de la sociedad argentina.

La nueva decisión del gobierno nacional se plasmó también en términos presupuestarios. Hasta el año 2003, el Programa 26 para la Promoción de Derechos Humanos (el principal programa con esta finalidad enmarcado en el Ministerio de Justicia y DDHH), incluía una serie de objetivos que se basaban en una noción ampliada de Derechos Humanos (recopilación de datos, campañas de promoción y preservación de los DDHH de acuerdo principalmente a las convenciones internacionales) 
(ARGENTINA, 2002-2017) ${ }^{16}$. En el Proyecto de Presupuesto del año 2003 (elaborado durante el 2002, bajo la presidencia de Eduardo A. Duhalde), se incluyó por primera vez entre los objetivos del programa acciones dirigidas a víctimas de violaciones de los DDHH durante la última dictadura militar:

Vela por el cumplimiento de las normas que reconocen y reglamentan el ejercicio de los derechos humanos en el ámbito nacional, implementando el cumplimiento de leyes de carácter reparatorio, dictadas 0 a dictarse en la materia, y mantiene actualizados los registros y archivos vinculados a las leyes No 24.043, No 24.411, No 24.321, No 24.499, No 24.823, No 25.192, No 25.457 y No 25.497. (ARGENTINA, 2002-2017). ${ }^{17}$

En el presupuesto previsto para el año 2005, se sumaron al programa las funciones del Archivo Nacional de la Memoria: "[...] desde el dictado del Decreto № 1259/03 recolecta, actualiza, preserva y digitaliza los archivos e informaciones vinculados a la vulneración de los derechos humanos por el terrorismo de estado, a través del Archivo Nacional de la Memoria." (ARGENTINA, 2002-2017).18

En el año 2007, se creó un nuevo programa vinculado a esta temática: Programa Verdad y Justicia, bajo la órbita de la Jefatura de Gabinete de Ministros (Decreto Nacional $n^{0} 606,22$ de mayo de 2007), que a partir del Decreto Nacional $n^{0}$ 589, 10 de abril de 2008) se traspasó al Min. de Justicia y DDHH de Nación (Programa $n^{0} 36$ ). Ese programa se creó para:

[... fortalecer el proceso de Verdad y Justicia, con la intención de centralizar en un organismo la coordinación de todas las dependencias del Poder Ejecutivo intervinientes en las investigaciones por los crímenes de lesa humanidad cometidos durante la última dictadura cívico-militar, como así también, garantizar la protección integral de las víctimas, testigos, querellantes y funcionarios involucrados en el proceso de juzgamiento por aquellos hechos. (ARGENTINA, 2014).

En conjunto, ambos programas obtuvieron un incremento progresivo del presupuesto tanto en números absolutos (Tabla 1 y Cuadro 4) como en su proporción relativa al presupuesto nacional (Tabla 1 y Cuadro 3). Aunque, en comparación con programas de otras jurisdicciones, es notable la variación que se observa del gasto interanual destinado a este conjunto de políticas. 
Tabla 1 - Evolución histórica 2001-2017 del Presupuesto destinado a los Programas n 26 y n 36

\begin{tabular}{|c|c|c|c|c|c|c|}
\hline Año & $\begin{array}{l}\text { A. Presupuesto } \\
\text { P. } 26\end{array}$ & $\begin{array}{c}\text { B. Presupuesto } \\
\text { P.36 }\end{array}$ & $\begin{array}{c}\text { C. } \\
\text { Presupuestos } \\
\text { p. } 26+36\end{array}$ & $\begin{array}{l}\text { D. Gasto del Sector } \\
\text { Público Nacional } \\
\text { Previsto }\end{array}$ & $C / D(\%)$ & $\begin{array}{l}\text { Variación } \\
\text { anual (\%) }\end{array}$ \\
\hline 2001 & $\$ 926.463$ & & $\$ 926.463$ & $\$ 51.232 .400 .000$ & $0,0018 \%$ & \\
\hline 2002 & $\$ 1.062 .578$ & & $\$ 1.062 .578$ & $\$ 42.844 .500 .000$ & $0,0025 \%$ & 37,15 \\
\hline 2003 & $\$ 1.148 .929$ & & $\$ 1.148 .929$ & $\$ 66.173 .000 .000$ & $0,0017 \%$ & $-29,99$ \\
\hline 2004 & $\$ 2.753 .210$ & & $\$ 2.753 .210$ & $\$ 59.708 .600 .000$ & $0,0046 \%$ & 165,58 \\
\hline 2005 & $\$ 7.814 .155$ & & $\$ 7.814 .155$ & $\$ 77.454 .000 .000$ & $0,0101 \%$ & 118,79 \\
\hline 2006 & $\$ 20.472 .075$ & & $\$ 20.472 .075$ & $\$ 93.702 .400 .000$ & $0,0218 \%$ & 116,56 \\
\hline 2007 & $\$ 27.546 .955$ & & $\$ 27.546 .955$ & $\$ 133.181 .900 .000$ & $0,0207 \%$ & $-5,33$ \\
\hline 2008 & $\$ 45.785 .510$ & & $\$ 45.785 .510$ & $\$ 161.486 .500 .000$ & $0,0284 \%$ & 37,08 \\
\hline 2009 & $\$ 100.620 .691$ & $\$ 10.823 .525$ & $\$ 111.444 .216$ & $\$ 253.483 .700 .000$ & $0,0440 \%$ & 55,07 \\
\hline 2010 & $\$ 96.130 .873$ & $\$ 5.760 .361$ & $\$ 101.891 .234$ & $\$ 296.610 .400 .000$ & $0,0344 \%$ & $-21,87$ \\
\hline 2011 & $\$ 127.769 .900$ & $\$ 10.786 .761$ & $\$ 138.556 .661$ & $\$ 405.720 .300 .000$ & $0,0342 \%$ & $-0,59$ \\
\hline 2012 & $\$ 193.079 .677$ & $\$ 9.988 .532$ & $\$ 203.068 .209$ & $\$ 547.074 .600 .000$ & $0,0371 \%$ & 8,69 \\
\hline 2013 & $\$ 249.148 .521$ & $\$ 7.855 .995$ & $\$ 257.004 .516$ & $\$ 685.665 .500 .000$ & $0,0375 \%$ & 0,98 \\
\hline 2014 & $\$ 403.793 .624$ & $\$ 12.744 .364$ & $\$ 416.537 .988$ & $\$ 927.585 .200 .000$ & $0,0449 \%$ & 19,80 \\
\hline 2015 & $\$ 716.304 .439$ & $\$ 24.815 .064$ & $\$ 741.119 .503$ & $\$ 1.347 .844 .600 .000$ & $0,0550 \%$ & 22,45 \\
\hline 2016 & $\$ 717.596 .460$ & $\$ 23.315 .095$ & $\$ 740.911 .555$ & $\$ 1.705 .076 .600 .000$ & $0,0435 \%$ & $-20,97$ \\
\hline 2017 & $\$ 607.542 .535$ & $\$ 11.928 .687$ & $\$ 619.471 .222$ & $\$ 2.550 .931 .300 .000$ & $0,0243 \%$ & $-44,11$ \\
\hline
\end{tabular}

Fuente: Elaboración propia en base a: ARGENTINA. Ministerio de Hacienda de la Nación. Proyecto de Presupuesto de la Administración Nacional (Datos: Gasto Total previsto) 2001 al 2017. Buenos Aires, 2001-2017. Disponible en: https://www.minhacienda.gob.ar/onp/presupuestos/2018. Acceso el: 15 ago. 2018.

Los crecimientos más importantes se dieron en los años 2004, 2005 y 2006, superando el $100 \%$ interanual (proporcionalmente con el presupuesto nacional), donde se pasó de un gasto previsto (solo para el programa 26) del $0,0017 \%$ en 2003 a un $0,0218 \%$ en 2006 . Luego, hubo otro gran incremento en el año 2009 (cuando fue incorporado a la órbita del Ministerio el Programa 36) con un $55,1 \%$ de crecimiento interanual y el último incremento significativo se dio en el año 2015 (22,5\% interanual), cuando se alcanzó el presupuesto máximo para el área, representando el 0,055\% del gasto previsto para el sector público nacional (Cuadro 3).

En el año 2010, se dio la baja más significativa en la tendencia de incremento proporcional que se venía asignando a estos programas, con una caída interanual de casi el -22\% y luego en el 2011, con un -0,6\%. No volvió a reducirse hasta el año 2016 (-21\%), cayendo luego estrepitosamente en el presupuesto previsto para el 2017 (-44\% interanual), lo cual significó un retroceso al nivel de gasto cercano a los valores del año 2007. Aunque si observamos la tendencia de asignación presupuestaria en pesos, las caídas se dieron sólo en el año 2010 y 2017 (Cuadro 4). 
Cuadro 3 - Evolución del Presupuesto destinado a los Programas 26 y 36 en relación al Gasto en el Sector Público Nacional Total (2001-2017)

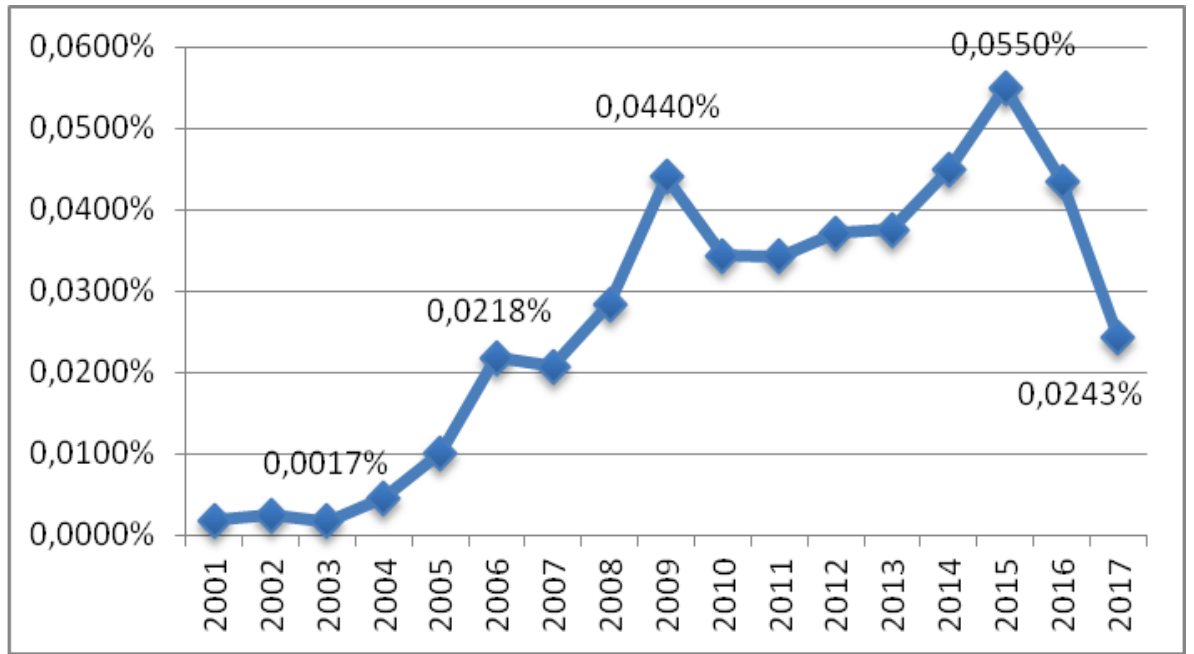

Fuente: Elaboración propia en base a Argentina (2001-2017).

\section{Cuadro 4 - Presupuesto destinado a los Prog. 26 y 36 (2001-2017)}

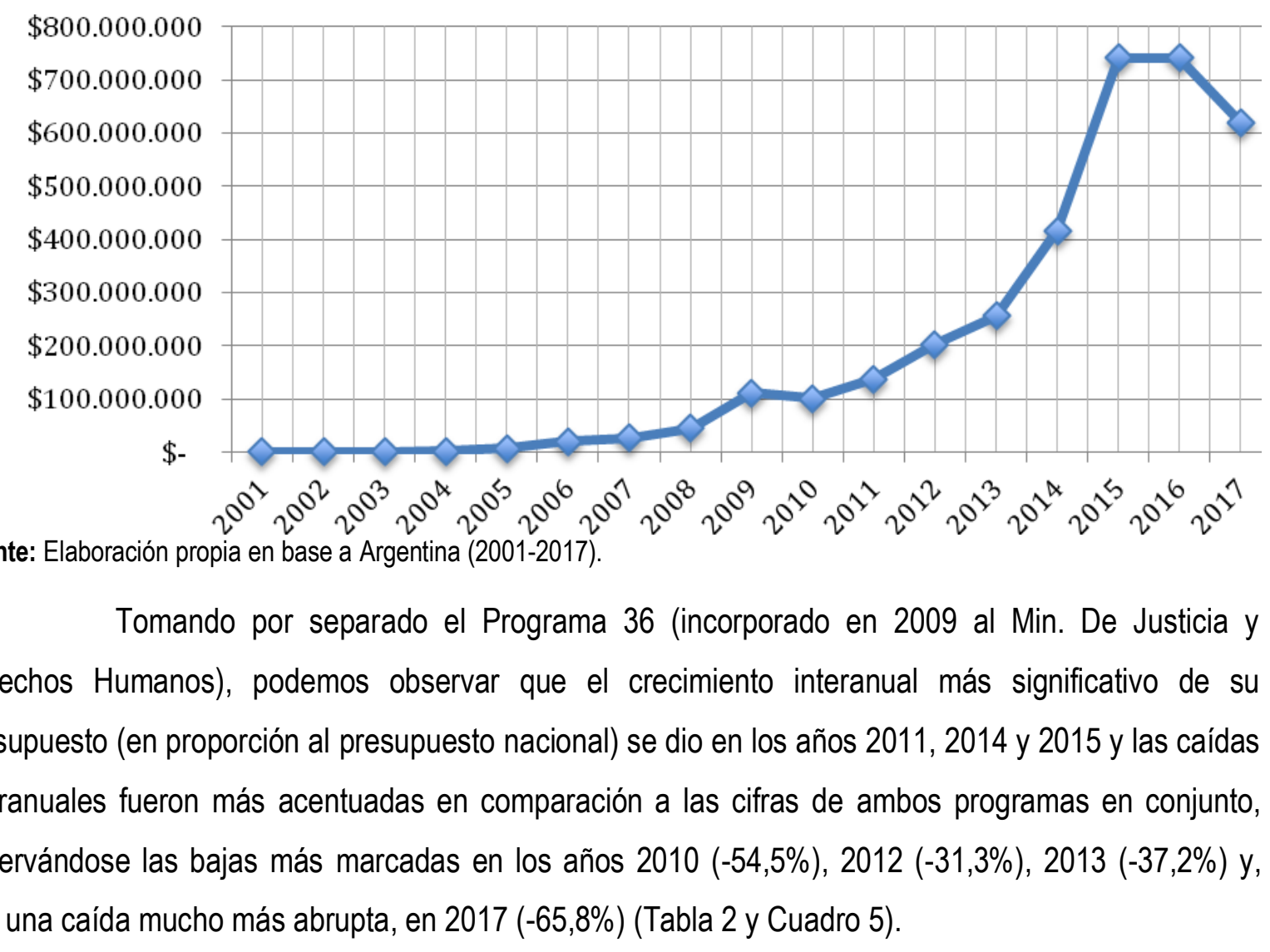


Tabla 2 - Evolución histórica 2009-2017 del Presupuesto Destinado al Programa № 36

\begin{tabular}{lcccc}
\hline Año & Presupuesto P. 36 & $\begin{array}{c}\text { P. 36/Gasto } \\
\text { Nacional }\end{array}$ & Variación anual & $\begin{array}{c}\text { Gasto del Sector Público } \\
\text { Nacional Previsto }\end{array}$ \\
$\mathbf{2 0 0 9}$ & $\$ 10.823 .525$ & $0,0043 \%$ & - & $\$ 253.483 .700 .000,00$ \\
$\mathbf{2 0 1 0}$ & $\$ 5.760 .361$ & $0,0019 \%$ & $-54,52 \%$ & $\$ 296.610 .400 .000,00$ \\
$\mathbf{2 0 1 1}$ & $\$ 10.786 .761$ & $0,0027 \%$ & $36,90 \%$ & $\$ 405.720 .300 .000,00$ \\
$\mathbf{2 0 1 2}$ & $\$ 9.988 .532$ & $0,0018 \%$ & $-31,33 \%$ & $\$ 547.074 .600 .000,00$ \\
$\mathbf{2 0 1 3}$ & $\$ 7.855 .995$ & $0,0011 \%$ & $-37,25 \%$ & $\$ 685.665 .500 .000,00$ \\
$\mathbf{2 0 1 4}$ & $\$ 12.744 .364$ & $0,0014 \%$ & $19,92 \%$ & $\$ 927.585 .200 .000,00$ \\
$\mathbf{2 0 1 5}$ & $\$ 24.815 .064$ & $0,0018 \%$ & $34,00 \%$ & $\$ 1.347 .844 .600 .000,00$ \\
$\mathbf{2 0 1 6}$ & $\$ 23.315 .095$ & $0,0014 \%$ & $-25,73 \%$ & $\$ 1.705 .076 .600 .000,00$ \\
$\mathbf{2 0 1 7}$ & $\$ 11.928 .687$ & $0,0005 \%$ & $-65,80 \%$ & $\$ 2.550 .931 .300 .000,00$ \\
\hline
\end{tabular}

Fuente: Elaboración propia en base a Argentina (2001-2017).

\section{Cuadro 5 - Evolución del presuposto destinado al Prog. 36 (2009-2017)}

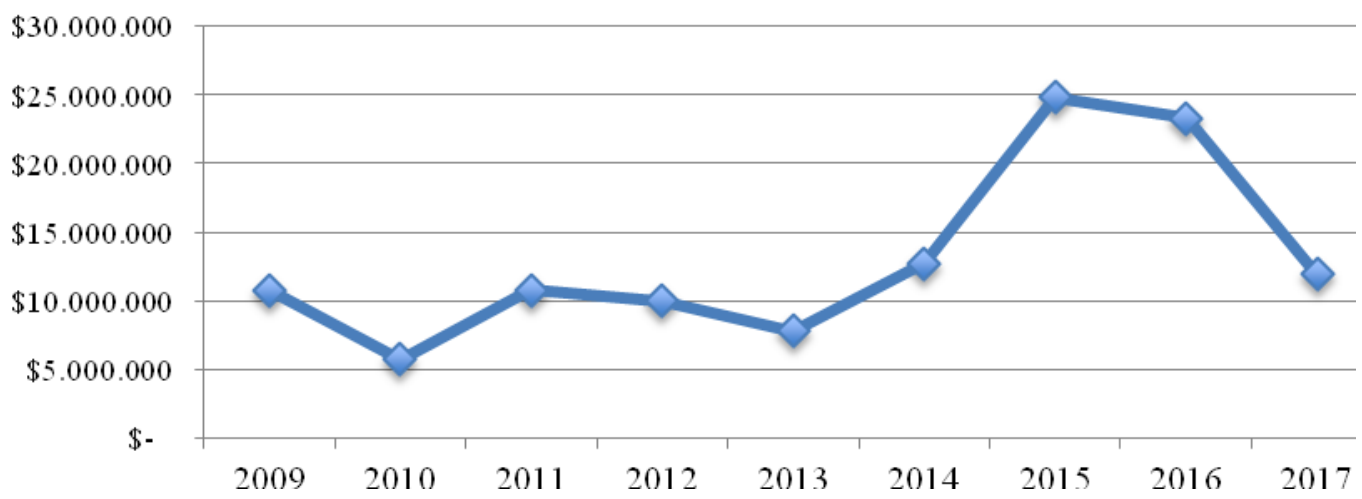

Fuente: Elaboración propia en base a Argentina (2001-2017).

Paradójicamente, los años donde disminuyó el presupuesto de manera continuada (20122013) fueron aquellos donde se dio la mayor cantidad de finalización de juicios por crímenes de lesa humanidad (Cuadro 1).

Otro indicador de la jerarquización del área de DDHH puede ser la cantidad de recursos humanos asignados. Si observamos los períodos presidenciales, podemos notar que tanto en la Presidencia de Néstor Kirchner como en los dos períodos de Cristina Fernández de Kirchner se incrementaron los cargos en el Programa 26 de manera progresiva. Para el período 2003-2007 se pasó de 58 a 88 cargos (+52\%); en el período 2007-2011 se dio el crecimiento más grande, pasando de 88 a 257 cargos $(+192 \%)$ y entre el 2011 y el 2015 se pasó de 257 a $363(+41 \%)$. Tomando los años de manera individual, los crecimientos interanuales más significativos se dieron en el 2007 (37,5\%), 2009 $(59,6 \%)$ y $2011(73,7 \%)$-coincidiendo con los años electorales-. (Cuadro 6) 


\section{Cuadro 6 - Cantidad de cargos absolutos (RRHH) para el Prog. 26 (2001-2015)}

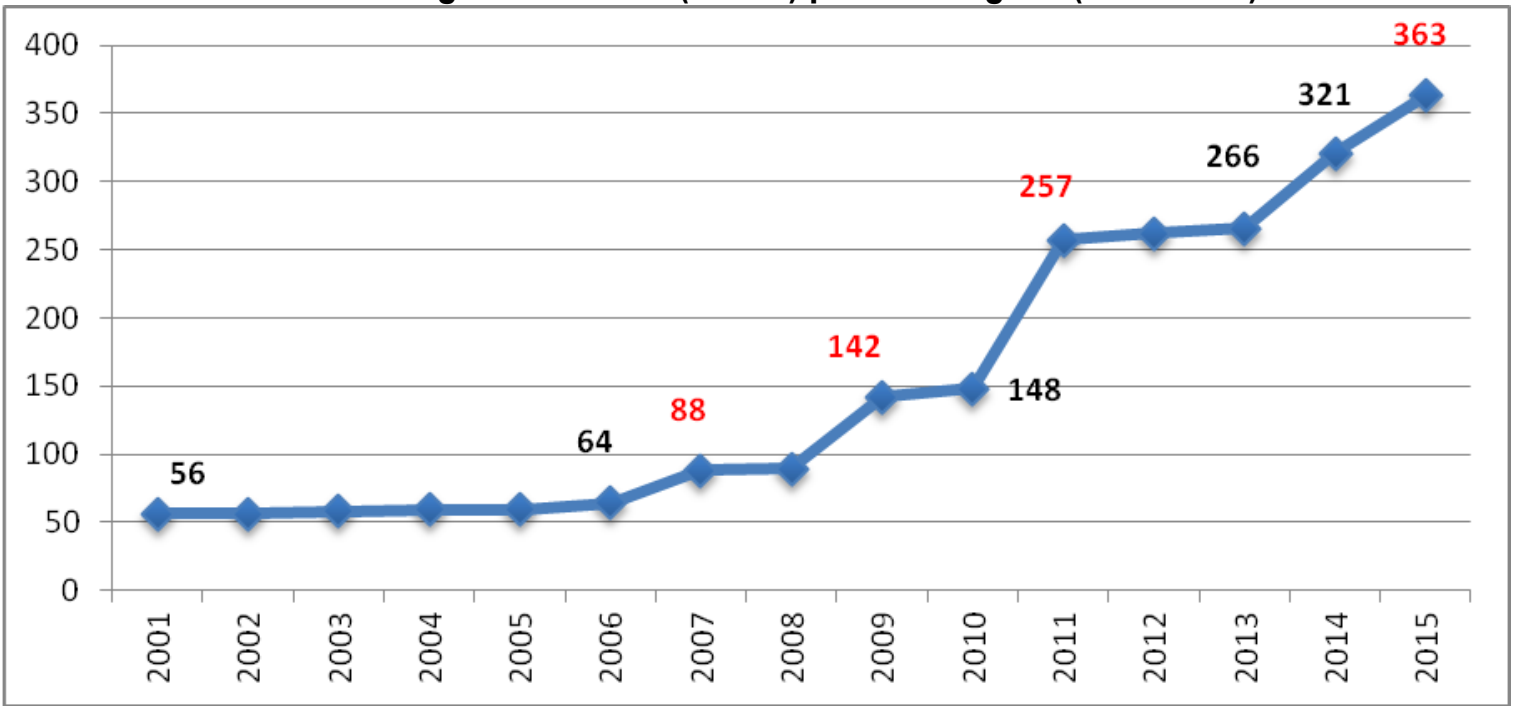

Fuente: Elaboración propia en base a Argentina (2001-2017).

Si bien las tendencias de inversión en esta área específica se incrementaron casi de manera ininterrumpida entre el 2004 y el 2015, las representaciones sobre el gobierno por parte de las organizaciones que conforman el MDH no fueron las mismas en cada uno de los períodos presidenciales, variaron entre organizaciones y no tuvieron siempre relación directa con los incrementos o caídas del gasto en políticas públicas afines a sus causas.

\section{EL "ESTADO" EN LA VOZ DE LAS ORGANIZACIONES DE DERECHOS HUMANOS: el} encuentro memoria, verdad y justicia y las organizaciones de familiares

Durante el año 2004, tuvo lugar una serie de políticas y acciones gubernamentales cargadas de un gran simbolismo para las organizaciones de DDHH. A pocos meses de iniciada la Presidencia de Néstor Kirchner, con motivo del 24 de marzo se realizó un acto en donde había funcionado la ESMA anunciando su recuperación como Espacio para la Memoria y luego, el propio Presidente ordenó al Jefe del Ejército descolgar los cuadros de los ex presidentes de factos Jorge R. Videla y Reynaldo B. Bignone en el Círculo militar. También fueron anunciadas nuevas políticas reparatorias para las víctimas y, acompañando estas acciones, el Presidente pidió en un acto público "[...] perdón de parte del Estado nacional por la vergüenza de haber callado durante 20 años de democracia por tantas atrocidades." (KIRCHNER, 2004).

Sin embargo, a excepción de la Asociación Madres de Plaza de Mayo ${ }^{19}$, a comienzos de 2004 la mayoría de las organizaciones del MDH se mostraba distante de las políticas del nuevo gobierno. El documento leído en Plaza de Mayo por el EMVyJ con motivo de acto del 24 de marzo de 2004, reconoció como un triunfo la anulación de las leyes de Obediencia debida y Punto Final, la declaración de imprescriptibilidad de los crímenes de la dictadura y la recuperación del espacio de la 
Ex ESMA, pero criticó fuertemente las políticas económicas que hasta ese momento se anunciaban, denunciando presupuesto insuficiente para áreas como salud y educación; llegando a decir que "[...] los principales problemas que llevaron al Argentinazo siguen vigentes" (EMVyJ apud VALES, 2004):

Todos los que estamos en esta Plaza tenemos claro que nuestra lucha para terminar con la impunidad de los genocidas de la dictadura [...] no se agota alli. Sabemos que esa lucha incluye terminar con la impunidad de los genocidas de hoy: los que matan de hambre, de miseria, de frío, de desocupación. (EMVyJ apud VALLES, 2004).

A pesar de estos hitos que tuvieron gran visibilidad y repercusión, no fue sino hasta el 2006 que el presupuesto destinado a la promoción de DDHH se incrementó de manera más significativa. Este año, también comenzaron a abrirse los procesos judiciales por causas de lesa humanidad, obteniéndose la primera condena a partir de la anulación de las Leyes de Obediencia Debida y Punto Final. Casualmente (o no tanto), este año se desencadenó la ruptura del EMVyJ que venía nucleando a más de 200 organizaciones sociales, políticas y especificas de DDHH y familiares de víctimas desde el año 1996. Luego de leerse el documento habitual durante el acto del 24 de marzo, algunas de las organizaciones de DDHH más importantes (APdM, MPdM, FDDRP, HDVJ, la Asamblea Permanente por los DDHH y Servicio de Paz y Justicia) publicaron una solicitada en el Diario Página 12 (ORG. DE FAMILIARES, 2006), rechazando el contenido de ese documento y aduciendo que no habían acordado ni firmado lo leído en ese acto. A partir de aquel momento, las organizaciones de APdM, MPdM, FDDRP e H.I.J.O.S. (sumándose HDVJ sólo algunos años) comenzarían a presentar un documento independiente en los actos del 24 de marzo (nos referiremos a este grupo de organizaciones como Org. de familiares de aquí en adelante).

Las divergencias entre ambos grupos se continuaron desarrollando durante los años siguientes y el acto del 24 de marzo de 2009 se hizo particularmente notable. Este año se destacó sustancialmente la inversión pública en el área de DDHH: el gasto en los programas de promoción de DDHH (Tabla 1 y Cuadro 3) fue el más alto desde la 2004 (superándose luego sólo en los años 2014 y 2015). También se sancionó una nueva ley reparatoria para víctimas y de jerarquización del CONADI, al mismo tiempo que continuaron de manera creciente los procesos judiciales finalizados y el número de acusados por crímenes de lesa humanidad.

A pesar de estos avances en las demandas reclamadas históricamente por el MDH, el documento del EMVyJ no refleja una interpretación positiva del gobierno y sus políticas (acusando inacción por parte del Estado, el gobierno, jueces, fiscales y legisladores):

La política oficial solo impulsa que aquellos jóvenes que duden de sus orígenes, se hagan una prueba genética. Una vez más las víctimas deben hacerse cargo de lo que es responsabilidad del Estado. [...] cientos de causas están literalmente paralizadas [...] Nada hace el Gobierno ni sus legisladores para modificar esta situación. [...] Los fiscales no cumplen su rol de investigar, sistematizar la prueba y acusar a todos. [...]. Tampoco la Secretaría de DDHH aporta a las causas los listados de personal de esos centros que tiene el Estado en sus archivos, ni impulsa el procesamiento de todos, ni denuncia a los fiscales y 
jueces que demoran las causas. [...] Desarmar la impunidad, construida prolijamente durante años, desarmar el aparato represivo de la dictadura, requiere de mucho más que discursos, requiere de una decisión política que el Gobierno no tiene. (ENCUENTRO MEMORIA, VERDAD Y JUSTICIA, 2009, p. 3, grifo original).

Asimismo, el análisis de los procesos judiciales fue negativo:

[...] a pesar de lo que dice el Gobierno, a más de 5 años y medio de anuladas las leyes de impunidad, el 95\% de los genocidas están libres. [...] No admitimos esta falsa polémica entre la Corte y el Gobierno. Sabemos y denunciamos que los responsables SON LOS JUECES Y ES EL GOBIERNO. (ENCUENTRO MEMORIA, VERDAD Y JUSTICIA, 2009, p. 2)

En este sentido, también el reclamo a la Justicia se hace evidente a lo largo de todo el documento de las Org. de familiares (2006, p. 1), el cual está marcado por una crítica directa a la Corte Suprema y otras agencias judiciales por su lentitud para tratar las causas de lesa humanidad:

[...] todavía falta mucho. Lamentablemente tenemos que decir que a 25 años del retorno de la democracia y a 5 años de la nulidad de las leyes de impunidad y la reapertura de las Causas aún continua la deuda de Memoria, Verdad y Justicia con las víctimas, sus familiares y la sociedad. Porque cuando la justicia es lenta no es justicia, sino apenas un consuelo.

Sin embargo, la crítica generalizada a la política oficial que se lee en el documento del EMVyJ no se identifica para este segundo caso. La principal crítica al Estado se da por lo insuficiente de su accionar, afirmando que "[...] aún continúa la deuda de Memoria, Verdad y Justicia con las víctimas, sus familiares y la sociedad" pero se matiza reconociendo que a lo largo de estos 30 años se obtuvieron victorias, que los juicios están en marcha y que existe un acompañamiento del Estado:

Este año miles de personas circularán por los tribunales de todo el país y es imprescindible que puedan encontrar no sólo un Estado que los acompañe sino también un Estado que haga todo lo que esté a su alcance y más, para cumplir con su obligación de brindar protección integral y garantizar el acceso a una justicia plena. (ORG. DE FAMILIARES, 2006, p. 2).

Un año después, el único año donde disminuyó en números absolutos el monto destinado a programas de DDHH durante los gobiernos kirchneristas, las Org. de familiares (2007-2016) leyeron un documento donde los reconocimientos a las políticas estatales fueron explícitas y se llevaron gran parte de su discurso: "Son muchos los motivos que nos traen a esta plaza cada año: venimos a repudiar el golpe cívico-militar del 76. (...) Pero en esta oportunidad, venimos a reconocer lo que conquistamos, lo que conseguimos con la lucha de todos [...]".

Con motivo de los balances por el bicentenario de la Revolución de Mayo, esas organizaciones interpretaban ese contexto político como esperanzador en términos de conquista de demandas, remarcando la excepcionalidad del momento histórico (aunque siempre recordando las demandas vigentes):

Hoy es un día histórico. Estamos viviendo momentos históricos. Este encuentro se da en el marco de ocho Juicios Orales y Públicos a los genocidas. Y se espera que a lo largo del año comiencen cinco más. Pero no es suficiente: necesitamos que se aceleren los Juicios y todos los genocidas sean condenados. (ORG. DE FAMILIARES, 2007-2016). 
Por su parte, el documento del EMVyJ repitió casi textualmente las críticas presentadas el año anterior, con la salvedad de mencionar la conquista que representó el avance de los juicios; aunque atribuyéndoselo netamente como un triunfo histórico del pueblo argentino. "Todos los que estamos en esta Plaza, los miles y miles de compañeros que venimos luchando por Memoria, Verdad y Justicia, sabemos que este triunfo es producto de la lucha de nuestro pueblo durante más de treinta años contra la impunidad. (ENCUENTRO MEMORIA, VERDAD Y JUSTICIA, 2010).

Además de sumarse críticas a la política económica del gobierno, se hizo hincapié en el repudio a los procesos en marcha de criminalización de la protesta: "El Gobierno que se autoproclama 'defensor de los DD.HH' utiliza una bandera tan cara a nuestro pueblo para enmascarar la impunidad mientras reprime y usa patotas contra los luchadores populares". (ENCUENTRO MEMORIA, VERDAD Y JUSTICIA, 2010, p. 3).

Por último, nos parece interesante analizar los documentos leídos en el acto del 24 de marzo de 2016, año significativo para la lucha de DDHH por cumplirse 40 años desde el golpe de 1976 y marcado por la transición presidencial de signos políticos cuasi opuestos, a partir de la llegada de $\mathrm{M}$. Macri a la Presidencia en diciembre de 2015. Por este motivo, gran parte de los documentos leídos en los actos constituyen un balance del período kirchnerista y un análisis de las primeras políticas del nuevo gobierno en Nación.

El documento del EMVyJ presentó críticas explícitas a los gobiernos de N. Kirchner y C. Fernández de Kirchner, como también al de M. Macri. En líneas generales, sostuvieron que todos los gobiernos constitucionales posteriores a la dictadura habrían perpetuado la impunidad en relación a los crímenes cometidos en aquel entonces por el Estado. Con respecto a los avances de los juicios, una vez más remarcaron que si bien fueron una conquista, resultaron insuficientes y "[...] son una conquista extraordinaria de la movilización popular y no de ningún gobierno." (ENCUENTRO MEMORIA, VERDAD Y JUSTICIA, 2016, p. 2).

En este sentido, hicieron una crítica directa a los gobiernos anteriores y al aparato judicial:

Los gobiernos de Néstor y Cristina Kirchner, que disponian de los recursos políticos para agilizarlos, no lo hicieron y así en cada uno de estos juicios nos enfrentamos a un aparato judicial que actúa como garante de la impunidad. [...] El Estado no aportó ni una sola prueba contra los represores: los juicios se sustancian exclusivamente con el testimonio y el aporte de sobrevivientes y familiares. (ENCUENTRO MEMORIA, VERDAD Y JUSTICIA, 2016, p. 2).

En relación al gobierno de Macri, además de numerosas críticas por sus políticas económicas y sociales, disintieron marcadamente de su postura en relación a los DDHH:

Estamos aquí, frente a un nuevo gobierno, el de Macri, con su política de ajuste, entrega y represión y su planteo de "reconciliación", contrario a la memoria, la verdad y la justicia. [...] El Secretario de DD. HH., Claudio Avruj, propone mandar a los genocidas condenados a sus casas y recibe a los familiares de los militares genocidas como si fueran víctimas. [...] Macri nombra a genocidas como funcionarios de su gobierno. (ENCUENTRO MEMORIA, VERDAD Y JUSTICIA, 2016, p.1). 
El balance por los 40 años del grupo de Org. de familiares compartió elementos con el de EMVyJ, pero se diferenció sustancialmente en su ponderación del período kirchnerista:

En estas décadas, los genocidas pasaron más años con impunidad que presos donde deben estar: en la cárcel común, perpetua y efectiva. [...] Esa historia empezó a cambiar en el 2003, con el Presidente Néstor Kirchner, quien decidió sacarle las vallas a la historia e incluir en políticas de Estado la lucha del pueblo por la Memoria, la Verdad y la Justicia. (ORG. DE FAMILIARES, 2007-2016, p. 2).

Con respecto al avance de los juicios, este grupo sí asoció esta conquista con el impulso llevado adelante por los gobiernos anteriores:

Así, con la continuidad y profundización de las Presidencias de Cristina Fernández, llegamos a estos 40 años del Golpe con más de 660 genocidas condenados, 119 identidades restituidas, más de 130 ex centros clandestinos señalizados y 35 espacios de memoria puestos en funcionamiento. La Memoria, la Verdad y la Justicia ya no son un imposible: son una de las victorias que vamos a seguir defendiendo a diario. (Org. de Familiares, 20072016, p. 2).

La lectura sobre el Estado realizada por estas organizaciones, se asociaba fuertemente al gobierno de turno que pone en marcha una serie de políticas de Estado, cuyo contenido deriva en la caracterización de un Estado terrorista (como el que se configuró durante la dictadura militar), un Estado para el pueblo, o un Estado a espaldas del pueblo:

Después de más de 12 años de un proyecto de inclusión, hoy las políticas de Estado empiezan a ser de exclusión social, política, económica y cultural. [...] La necesidad y urgencia que los corría era la de desarmar el país que teníamos, integrado a la Patria Grande y con un Estado para el pueblo. Lo cambiaron por un país entregado a las corporaciones y con un Estado de espaldas al pueblo, con lógicas empresariales y el vaciamiento de políticas sociales fundamentales para garantizar derechos. (ORG. DE FAMILIARES, 2007-2016, p. 2).

Las críticas al gobierno de Macri también fueron recurrentes y directamente vinculadas a su política de $\mathrm{DDHH}$, denunciando el recorte en esta área:

El gobierno tiene un doble discurso que hay que denunciar: mientras declara a la prensa que los juicios a los genocidas continuarán, despide a los trabajadores y trabajadoras que sostienen las políticas de Estado que los garantizan, como el acompañamiento a testigos y la investigación para las causas. [...] Las políticas de Memoria, Verdad y Justicia, como cualquier otra que garantice derechos, sólo se sostienen con los trabajadores y trabajadoras adentro. (ORG. DE FAMILIARES, 2007-2016, p. 2).

En su reclamo general contra la violencia institucional, se afianzó esta crítica por el recorte en ciertas áreas ejecutado por el gobierno de Macri, planteando la necesidad de un Estado comprometido, como también hicieron referencia a que todos los estados y gobiernos tuviesen como obligación aportar a la Memoria, la Verdad y la Justicia.

Como pudimos ver en el apartado anterior, el recorte en el área de DDHH que planearía el nuevo gobierno nacional para el año 2017 fue el más grande desde el 2004, alcanzando una caída de casi $40 \%$ interanual. Aunque esto aún no se conocía en marzo del 2016 , era palpable otro tipo de políticas que podrían anticipar la dirección del gobierno en esta área, como el recorte de personal en 
oficinas públicas dependientes del Ministerio de Justicia y $\mathrm{DDHH}$, los discursos de funcionarios públicos sobre el pasado reciente con interpretaciones contrarias a la promovida por el MDH y gestos, como la invitación del presidente de EEUU de aquel entonces, Barack Obama, para que visitara la Argentina durante el 24 de marzo; acontecimiento que sería repudiado por todas las organizaciones de $\mathrm{DDHH}$ (fundamentalmente por el EMVyJ) por asociar a la figura de Obama como representante de un Estado que promovió el proceso dictatorial en Argentina.

\section{CONCLUSIONES}

Lejos de postular que los actores políticos reaccionan de manera automática a los incentivos económicos, lo que podemos observar en este trabajo exploratorio es que la relación entre la actitud de las organizaciones del MDH hacia un gobierno y sus representaciones más generales sobre el Estado se configuran de manera compleja, incidiendo diversos factores: si bien influye la existencia o no de incentivos materiales, también lo hace la existencia de factores del orden simbólico (como los gestos públicos por parte de funcionarios estatales, el reconocimiento de sus trayectorias y demandas, entre otros); la interpretación que los actores hacen de esos elementos; la coyuntura histórica en el que se enmarcan estos procesos (cómo los actores interpretan los procesos políticos más amplios, por ejemplo, en términos de continuidad o ruptura) y a su vez, la historia de cada uno de esos actores colectivos involucrados, cuyas diferencias en términos de trayectoria y articulación de redes políticas se traducen en marcos interpretativos divergentes acerca del Estado.

En los ejemplos analizados, observamos que no hay una linealidad entre la variación del presupuesto destinado a los Programas 26 y 36 del Ministerio de Justicia y Derechos Humanos y los cambios de actitud hacia el Estado que se pone de manifiesto en los documentos leídos durante los actos conmemorativos del 24 de marzo. Encontramos que años de baja inversión en DDHH (como el 2010) reflejan una mirada positiva sobre el Estado por parte de las Org. de Familiares (quizás también por efecto acumulativo de las políticas implementadas años anteriores) y, mientras que en el 2016 el mismo grupo realizaba un balance destacando las conquistas obtenidas durante los gobiernos de Néstor Kirchner y Cristina Fernández de Kirchner, el documento del EMVyJ es el que presentaba las críticas más duras a esos gobiernos y las políticas estatales de todo el período analizado.

Dos grupos que, en principio, se articulan en torno a una causa común, que comparten demandas y obtienen determinadas respuestas como fruto de su interpelación al Estado, construyen marcos interpretativos muy diferentes no sólo en relación a los gobiernos, sino también a otras agencias estatales (vinculados al Poder Legislativo y Judicial o instituciones estatales de diferentes niveles). Aunque en muchos casos es común encontrar representaciones sobre el Estado cuya carga valorativa se asocia a las interpretaciones sobre el gobierno de turno, es notable cómo la noción de 
Estado comienza a aparecer de manera creciente en los documentos de las organizaciones desde el año 2004 (cuando antes sólo aparecía vinculada al terrorismo de Estado de los años setenta) y también se diversifica su interpelación, conducida ahora a los tres poderes y fundamentada en la responsabilidad que se le atribuye al Estado de velar por la verdad y la justicia.

Creemos que ese caso permite mostrar cómo la movilización política puede influir en el reconocimiento de demandas por parte de Estado, la activación de políticas y, al mismo tiempo, cómo la implementación de políticas públicas de Derechos Humanos incide en el campo político, modificando a las organizaciones y sus relaciones. Skocpol (1996) llamará a este proceso la retroalimentación de las políticas públicas, las cuales habilitan, por un lado, la transformación o expansión de las capacidades del Estado, y en otro plano, afectan a las identidades sociales, objetivos y capacidades de los grupos que pugnan o se alían en la política.

Cabe mencionar, por último, que las fuentes disponibles y el recorte metodológico necesario, no permitieron realizar un análisis en profundidad de las representaciones sobre el Estado compartidas por las organizaciones de $\mathrm{DDHH}$, como también queda abierto el interrogante acerca de cómo influye la integración de miembros del MDH al aparato del Estado en la constitución y significación de la propia práctica estatal. Sin embargo, consideramos por lo señalado en un comienzo que el seguimiento de los documentos elaborados con motivo del 24 de marzo permite una aproximación al objeto, ilustrando cambios, continuidades y contrastes en las interpretaciones y posturas tomadas en contextos históricos y políticos específicos.

\section{REFERENCIAS}

ANDRIOTTI ROMANIN, E. Actores, Estado y políticas públicas reparatorias en relación al terrorismo de Estado en Argentina (2003-2007). Sudamérica, Mar del Plata, n. 4, p. 136-155, 2015.

ANDRIOTTI ROMANIN, E. Cooptación, oportunidades políticas y sentimientos. La Asociación Madres de Plaza de Mayo de Argentina y el gobierno de Néstor Kirchner. Polis, Revista Latinoamericana, Santiago de Chile, v. 13, n. 39, p. 229-247, 2014.

ARGENTINA. Ministerio de Hacienda de la Nación. Política presupuestaria de la Jurisdicción $\mathbf{4 0}$ (Año 2002 a 2017). Buenos Aires, 2002-2017. Disponible en: https://www.minhacienda.gob.ar/onp/presupuestos/2018. Acceso el: 15 ago. 2018.

ARGENTINA. Ministerio de Hacienda de la Nación. Proyecto de Presupuesto de la Administración Nacional (Datos: Gasto Total previsto) 2001 al 2017. Buenos Aires, 2001-2017. Disponible en: https://www.minhacienda.gob.ar/onp/presupuestos/2018. Acceso el: 15 ago. 2018.

ARGENTINA. Ministerio de Justicia y Derechos Humanos, Secretaría de Derechos Humanos. Programa Verdad y Justicia, Informe de gestión 2014. Buenos Aires, 2014. Disponible en: http://www.jus.gob.ar/media/3114780/informe_final_gesti_n_2014.pdf. Acceso el: 15 ago. 2018. 
BRYSK, A. The Politics of Human Rights in Argentina: Protest, Change, and Democratization. Stanford: Stanford University Press, 1994.

CENTRO DE ESTUDIOS LEGALES Y SOCIALES. Estadísticas / proceso de Justicia delitos de lesa humanidad. Ciudad de Buenos Aires, 2016. Disponible en:

https://www.cels.org.ar/web/estadisticas-delitos-de-lesa-humanidad/. Acceso el: 30 sept. 2016.

ELSTER, J. Rendición de cuentas: la justicia transicional en perspectiva histórica. Buenos Aires: Katz, 2006.

ENCUENTRO MEMORIA, VERDAD Y JUSTICIA. Documento del "Encuentro Memoria, Verdad y Justicia" leído en el Acto del 24 de marzo. Buenos Aires, 2016. Disponible en:

<http://gacetillasargentinas.blogspot.com.ar/2016/03/documento-del-emvj-240316.html>. Acceso el: 15 ago. 2018.

ENCUENTRO MEMORIA, VERDAD Y JUSTICIA. Documento del "Encuentro Memoria, Verdad y Justicia" leído en el Acto del 24 de Marzo, Buenos Aires, 2009. Disponible en:

<https://encuentromvyj.org/documentos/>. Acceso el: 15 ago. 2018.

ENCUENTRO MEMORIA, VERDAD Y JUSTICIA. Documentos del "Encuentro Memoria, Verdad y Justicia" leídos en los Actos del 24 de Marzo. Buenos Aires, 2010. Disponibles en: https://encuentromvyj.org/documentos/>. Acceso el: 15 ago. 2018.

GASULLA, L. El negocio de los derechos humanos. Buenos Aires: Sudamericana, 2012.

GUEMBE, M. J. La experiencia argentina de reparación económica de graves violaciones a los derechos humanos. Buenos Aires: CELS, 2004.

KIRCHNER, N. Discurso en la Ex ESMA. Buenos Aires, 2004. Disponible en:

http://www.cfkargentina.com/museo-de-la-memoria-nestor-kirchner-en-la-esmal. Acceso el: 15 ago. 2018.

MONTERO, A. S. ¡Y al final un día volvimos! Los usos de la memoria en el discurso Kirchnerista. Buenos Aires: Prometeo, 2013.

MORALES, M. V. Asociación Madres de Plaza de Mayo: kirchnerismo y resignificación. In BARROS, M.; DAÍN, A.; MORALES, V. (eds). Escritos K. Villa María: Eduvin, 2012.

ORG. DE FAMILIARES. Comunicado y solicitada aparecida hoy en pagina 12 -Rechazos al documento. Buenos Aires, 2006. Disponible en:

http://argentina.indymedia.org/news/2006/03/389510.php. Acceso el: 15 ago. 2018.

ORG. DE FAMILIARES. Discursos con motivo del Acto del 24 de Marzo. H.I.J.O.S. Capital. Buenos Aires, 2007-2016. Disponible en: http://www.hijos-capital.org.ar/. Acceso el: 15 ago. 2018.

RETAMOZO, M. Movimientos sociales, política y hegemonía en Argentina. Polis - Revista latinoamericana, Santiago de Chile, v. 10, n. 28, p. 243-279, 2011

ROMERO, L. Breve Historia Contemporánea de la Argentina (1916-2010). Buenos Aires: Fondo de Cultura Económica, 2011. 
SKOCPOL, T. Los orígenes de la política social en Estados Unidos. Madrid: Ministerio de trabajo, 1996.

VALES, L. A 28 años del golpe con la Plaza llena. Diario página 12, Buenos Aires, 2004. Disponible en: https://www.pagina12.com.ar/diario/elpais/1-33235-2004-03-25.html. Acceso el: 15 ago. 2018.

\section{Notas}

${ }^{1}$ Nos referimos a los gobiernos de Néstor Kirchner (2003-2007) y Cristina Fernández de Kirchner (2007-2015).

2 Entendemos por políticas reparatorias a distintas decisiones y acciones tomadas por regímenes políticos para contrarrestar las consecuencias de los crímenes cometidos por regímenes políticos que los antecedieron. Estas presentan una variedad de opciones siendo su orientación general la búsqueda de la verdad, las purgas de aquellos involucrados en la comisión de crímenes, el establecimiento de compensaciones a las víctimas, el reconocimiento de responsabilidades políticas y la obtención de justicia, entre otras. (ELSTER, 2006).

3 El 24 de marzo de 2017 la presidenta de la Asociación Madres de Plaza de Mayo de Argentina , Hebe Pastor de Bonafini, manifestó que las madres habían dejado de ser una organización de derechos humanos para "[...] convertirse en un partido político identificado con el kirchnerismo". (Informação verbal).

${ }^{4}$ El tratamiento de las violaciones a los derechos humanos cometidas en Argentina entre los años 1975 y 1983 incluyó una amplia política de reparación económica. Al respecto véase Brysk (1994) e Guembe (2004).

${ }^{5}$ Este Ministerio modificó su denominación varias veces, pero siempre se identificó en el presupuesto bajo la Jurisdicción 40.

${ }^{6}$ Cambiemos es una coalición política nacional de Argentina fundada en 2015, a partir del acuerdo establecido entre la Coalición Cívica (ARI), Propuesta Republicana (PRO), la Unión Cívica Radical (UCR), entre otras agrupaciones políticas, triunfando en las elecciones presidenciales de ese año, con Mauricio Macri como candidato.

${ }^{7}$ Aniversario de golpe militar que en 1976 instauro la última dictadura militar en Argentina.

${ }^{8}$ El Encuentro Memoria Verdad y Justicia es un espacio de coordinación que existe desde el año 1996, formado para organizar la marcha en conmemoración por los 20 años del golpe de Estado de 1976, y desde ese año lo realizan de manera continuada hasta el presente, consensuando entre todas las agrupaciones participantes un documento común que se lee en los actos. Hasta el año 2006 reunió a la mayoría de las organizaciones de DDHH de la Argentina.

${ }^{9}$ En las instalaciones donde se encontraba la Escuela de Suboficiales de Mecánica de la Armada (ESMA), una institución educativa de la Armada ubicada en el barrio de Nuñez de la Ciudad Autónoma de Buenos Aires, durante la última dictadura militar funcionó uno de los principales centros clandestinos de detención del país.

10 Ver Said (2015), Espacios de memoria en la Argentina.

11 Ver otros decretos y leyes que jerarquizan ambos entes en Argentina (ARGENTINA, Ministerio de Justicia y Derechos Humanos, Secretaría de Derechos Humanos y Pluralismo Cultural, Normativa).

12 Ver en Argentina. Ministerio de Justicia y Derechos Humanos, Secretaría de Derechos Humanos y Pluralismo cultural, Archivo Nacional de la Memoria, Sitios de Memoria, Señalizaciones de Sitios de memoria.

${ }^{13}$ Conocidas popularmente como las leyes de impunidad, estas leyes sancionadas durante el gobierno de Raúl Alfonsín (1983-1989) permitieron la clausura del tratamiento punitivo del pasado dictatorial. La Ley de Punto Final fue sancionada en diciembre de 1986 y estableció un límite temporal de sesenta días para la presentación de denuncias judiciales por crímenes cometidos durante la dictadura. A su turno, la Ley de Obediencia Debida fue sancionada en junio de 1987 y estableció que aquellos que habían obedecido órdenes de sus superiores no podían ser juzgados por los crímenes de la dictadura. 
14 Durante la presidencia de Carlos Menem (1989-1999) se cerró el primer ciclo de pretensión punitiva mediante distintos decretos promulgados entre el 7 de octubre de 1989 y el 30 de diciembre de 1990 que indultaron a numerosos civiles y militares acusados, y algunos de ellos condenados, por la comisión de crímenes durante la dictadura militar.

${ }^{15}$ Oscar Fappiano (2002-2003), abogado que integró y llegó a presidir la Comisión Interamericana de Derechos Humanos y fue juez ad hoc de la Corte Interamericana de Derechos Humanos; Eduardo L. Duhalde (2003-2012) abogado y periodista con una larga trayectoria de militancia en DDHH (siendo él mismo un exiliado por persecución política durante el año 1976) y Martín Fresneda (2012-2015) abogado que asumió su cargo con 37 años de edad, contando con una militancia previa en la organización H.I.J.O.S.

16 Ver en Argentina - Política presupuestaria de la Jurisdicción 40 (Año 2002).

17 Ver en Argentina - Política presupuestaria de la Jurisdicción 40 (Año 2003).

18 Ver en Argentina - Política presupuestaria de la Jurisdicción 40 (Año 2005).

19 La Asociacion Madres de Plaza de Mayo inicio desde comienzos del gobierno de Nestor Kirchner un proceso de identificación con este. Al respecto ver Andriotti Romanin (2014). 